relatively small sample size they employed, I calculated the $95 \%$ confidence interval of their estimate of prevalence to see what happened if the similar studies were repeated in an independent setting (independent samples representing the population of the country) given the condition that the probability (prevalence) of developing the disease is assumed to be that obtained from the study of Honda $e t$ al and given the same sample size $(9000)$. This turned out to be 11.6-30.6 per 10000 . Although this wide interval indicates some uncertainty in the estimate, the low limit still exceeds the level of 10 per 10000 .

The possibility may arise, however, that their prevalence result in an overestimate. The prevalence of childhood autism in Honda et al's study could, in theory, be expected to be equivalent to their estimate of cumulative risk, if one assumed that children who moved out of that area with their parents over the five-year period were replaced by an influx of others at the same risk of developing the disorder. Instead, four children identified as having autism moved into the study area, whereas only one autistic girl moved out. The fact that there was attrition of 703 children in the 1988 birth cohort over the period studied, indicates a net outflow of that cohort from the area. As no information on the actual size of in- and outflow of the cohort is provided, it is impossible to estimate the risk, but it is probable that children at higher risk of autism were brought in by parents who might have understandably sought better care for their children afflicted with the condition. However, as the authors note, parents having an autistic child might have chosen to stay in the same area where it is easy to access special facilities and where well-organised education programmes are provided.

On the other hand, it is worth noting that all Japanese studies (six including that of Honda et al) but one, regardless of the size of denominators, have found a prevalence greater than 10 per 10000 . Some unique and societal factor may play a contributory role in better detection of the disorder. Despite the steady fall in the actual number of children in Japan, with a concomitant fall in the mean sibling number, the number of three-year-old children in nursery schools is increasing. This may reflect parents' anxiety about the development of communication skills in their children, particularly in urban areas. Even subtle problems in activities among peers could be readily brought to light in a society where children are compelled to start competitive racing at an increasingly earlier age and, furthermore, are culturally expected to assume a harmonious attitude as a member of group.

HondA, H., Stmazu, Y., Misuma, K., et al (1996) Cumulative incidence and prevalence of childhood autism in children in Japan. British Journal of Psychiatry, 169, 228-235.

Institute of Psychiatry

N. TAKEI

London SES 8AF, and

School of Health Sciences

University of Tokyo

Tokyo 113, Japan

\section{Nefazodone-induced spontaneous ejaculation}

SrR: The sexual side-effects of antidepressant drugs are frequent but under-recognised. They include decreased libido; impaired arousal/erection; delayed, absent, retrograde or painful ejaculation; and delayed or absent orgasm (Pollack et al, 1992). Nefazodone is considered to be superior to other antidepressant drugs by virtue of its relative lack of sexual side-effects (Feiger et al, 1996). We report a case of nefazodone-induced spontaneous ejaculation.

A 50-year-old man was referred with a first episode of major depression of six months' duration. He was sexually active, but the frequency of sexual intercourse and masturbation decreased from onset of the depression. He failed to respond to a series of antidepressants, including imipramine, sertroline, venlafaxine and lithium. He was then commenced on nefazodone $200 \mathrm{mg} /$ day, and lithium was continued. At the next follow-up, three weeks later, he reported that he had stopped the nefazodone because of an embarrassing and distressing side-effect; he had spontaneous ejaculations on average seven times a day. These were preceded by an urge to pass urine and were not associated with sexual thoughts, erection or any pleasurable sensations. These ejaculations stopped within 24 hours of discontinuing nefazodone. He was not keen on a nefazodone challenge. He had no sexual side-effects with any other antidepressant drugs.

Since this patient did not have sexual side-effects on any other antidepressant, the unique pharmacological characteristics of nefazodone, i.e. serotonin reuptake inhibition and $5-\mathrm{HT}_{2}$ receptor blockade (Feiger et al, 1996), resulting in the facilitation of $5-\mathrm{HT}_{1 \mathrm{~A}}$ neurotransmission, were probably responsible for this side-effect. Selective $5-\mathrm{HT}_{1 \mathrm{~A}}$ receptor agonists markedly facilitate male rat sexual 
behaviour, as evidenced by a dramatic reduction in the number of intromissions before ejaculation to one or two, rather than the more usual 10 or 12 (Pfaus \& Everitt, 1995). We did not have an opportunity to find out whether the ejaculations were dose-related or whether or not the patient would develop tolerance to this side-effect.

There are very few reports of psychotropic druginduced spontaneous emission and/or ejaculation. Brier et al (1984) reported a case of desipramineand imipramine-induced seminal emission following defaecation, without orgasmic sensations, in a patient with otherwise normal sexual function. Spontaneous ejaculation has also been reported with the antipsychotic zuclopenthixol (Williams \& O'Brien, 1994). Keitner \& Selub (1983) reported a case of spontaneous ejaculations with trifluoperazine and thiothixene. However, they occurred only in the presence of women and were associated with pleasurable orgasmic sensations, but partial or absent erections.

To our knowledge, this is the first report of spontaneous ejaculation induced by nefazodone. All antidepressant drugs have the potential to cause sexual side-effects, which can cause distress and reduce compliance with treatment.

Breier, A., Gnsberg, E. M. \& Charney, D. S. (1984) Seminal emission induced by tricyclic antidepressant. American Journal of Psychiatry, 141, 610-611.

Feiger, A., KIEv, A., Shrivastava, R. K., et al (1996) Nefazodone versus sertraline in outpatients with major depression: focus on efficacy, tolerability and effects on sexual function and satisfaction. Journal of Clinical Psychiatry, 57 (suppl. 2), 53-62.

KeIrNer, G. I. \& SelUB, S. (1983) Spontaneous ejaculation and neuroleptics. Journal of Clinical Psychopharmacology, 3, 34-36.

Praus, J. G. \& Everrrt, B. J. (1995) The pharmacology of sexual behaviour. In Psychopharmacology: The Fourth Generation of Progress (eds F. E. Bloom \& D. J. Kupfer), pp. 743-757. New York, NY: Raven Press.

Pollack, M. H., Retrer, S. \& Hammerness, P. (1992) Genitourinary and sexual adverse effects of psychotropic medication. International Journal of Psychiatry in Medicine, 22, 305-327.

WILLIAMs, J. \& O'BRIEN, J. (1994) Ejaculation associated with zuclopenthixol (letter). British Journal of Psychiatry, 165, 697.

A. Michaei

Addenbrooke's Hospital

Cambridge CB2 $2 Q Q$

R. RAMANA

Fulbourn Hospital

Cambridge CB1 SEF

\section{ONE HUNDRED YEARS AGO}

\section{Housing the Insane}

The supplement to the 50th Report of the Commissioners in Lunacy contains the plans of six new asylums, providing accommodation for nearly five thousand five hundred insane persons-London County building at Bexley Heath for 2,000, Lancashire for 2,000 (chronics) at Winwick, Stafford for 600 at Chedderton, West Sussex for 600 near Chichester, and Middlesbrough for 250.

The multiplication of asylums is so rapid, their cost so great, and their import so threatening that the question naturally suggests itself, is there no other way? Is it unavoidable that the great bulk of those suffering from mental disability must be housed in big institutions? If not, how else can they be provided for, and in what relative numbers?

Answers to these questions from an authoritative source are urgently needed to assist those upon whom the responsibility falls of providing for the increase of the insane, and certainly no body of men has greater knowledge or experience of this subject than the members of this Association.

The views of the members of this Association, whether individually or collectively expressed, should certainly be available for those needing information or guidance, and the Association would be only fulfilling a duty to the community in discussing, and, if possible, formulating its success on this question.

The London County Council has appointed a committee to inquire and report on this subject, so that the simultaneous consideration we have suggested would not be inopportune.

\section{Reference}

Journal of Mental Science, XLIII, January 1897, 112-113. 